Data de recebimento do artigo: 2-4-2018

Data de aceite do artigo: $23-7-2018$

\title{
Possibilidades de internacionalização do Curso de Secretariado Executivo na América do Sul
}

\author{
Débora Andrea Liessem Vigorena \\ Doutora em Administração pela Universidade Positivo. Docente do curso de Secretariado Executivo \\ da Unioeste. E-mail: d_vigorena@yahoo.com.br (Brasil)
}

\section{Maura Bernardon}

Doutora em Letras pela Universidade Federal da Bahia (UFBA). Docente do curso de Secretariado Executivo da Unioeste. E-mail: maabe70@yahoo.com.br (Brasil)

\section{Patrícia Stafusa Sala Battisti}

Doutora em Administração pela Universidade Positivo. Docente do curso de Secretariado Executivo da Unioeste. E-mail: patriciasala5@ hotmail.com (Brasil)

Caroline Alexandra de Barcellos

Graduada em Publicidade e Propaganda pela Faculdade Sul Brasil (Fasul). Graduada em Letras Inglês e Literaturas Correspondentes pela Universidade Estadual de Maringá (UEM).

E-mail: carolvigore@yahoo.com.br (Brasil)

\section{RESUMO}

Tendo em vista os ganhos institucionais advindos do processo de internacionalização da educação superior, este estudo tem como objetivo geral buscar possibilidades para ações de internacionalização entre o Curso de Secretariado Executivo (SE) da Universidade Estadual do Oeste do Paraná (Unioeste) e aqueles localizados em países sul-americanos. Como objetivo específico, pretende-se identificar os cursos de graduação que se assemelham à nomenclatura e à matriz curricular de formação do profissional de SE. A partir desse conhecimento, entende-se que haverá maior possibilidade de cooperação internacional a fim de fortalecer a formação dos estudantes, assim como contribuir com o processo de verticalização da área de SE. Para tanto, explana-se sobre conceitos de internacionalização da educação superior, bem como sobre a internacionalização do currículo. Trata-se de um estudo de caso comparativo, apoiado no método exploratório-descritivo e na técnica de coleta de dados secundários. Os resultados apontaram que, no contexto sul-americano, apenas o Equador oferta cursos de SE em nível superior em termos próximos aos do Brasil. Por um lado, a comparação entre as matrizes curriculares revelou muitas semelhanças entre as disciplinas da área secretarial; por outro lado, as disciplinas da área administrativa e comunicação demonstraram menores semelhanças. Essa dificuldade em encontrar cursos com maior compatibilidade sugere, como apontado na literatura, uma necessidade de maior flexibilização para a mobilidade acadêmica.

Palavras-chave: Internacionalização da educação superior. Matriz curricular. Secretariado Executivo. 


\title{
Possibilities on Internationalization of the Executive Secretariat Course in South America
}

\begin{abstract}
Considering the institutional gains derived from the internationalization of higher education process, this study has the general objective of searching for possibilities of internationalization actions between the Executive Secretariat (ES) undergraduate program of Universidade Estadual do Oeste do Paraná (Unioeste) and those located in South American countries. The specific objective is to identify courses that resemble the nomenclature and curriculum of ES professional education. Based on this knowledge, we understand there will be a greater possibility of international cooperation in order to strengthen the student's education, as well as contributing with the verticalization process of ES field. In order to achieve this goal, concepts of higher education curriculum internationalization were explored. This is a comparative case study, which is supported by the exploratory-descriptive method and the technique of secondary data collection. The results showed that only Ecuador offers undergraduate programs in close similarity to those in Brazil. On the one hand, the comparison between curricula revealed many similarities among the courses in the secretarial field; on the other hand, the administrative and communication courses showed fewer similarities. This difficulty in finding undergraduate programs with greater compatibility suggests, as pointed out in literature, a need for greater flexibility for the academic mobility.
\end{abstract}

Keywords: Higher education Internationalization. Curriculum. Executive Secretariat.

\section{Como referenciar em APA:}

Vigorena, D. A. L., Bernardon, M., Battisti, P. S. S., Barcellos, C. A. (2018). Possibilidades de Internacionalização do Curso de Secretariado Executivo na América do Sul. R.G.Secr.,GESEC, 9(3).

\section{Como referenciar em ABNT:}

VIGORENA, D. A. L.; BERNARDON, M.; BATTISTI, P. S. S.; BARCELLOS, C. Possibilidades de Internacionalização do Curso de Secretariado Executivo na América do Sul. R.G.Secr.,GESEC, v. 9, n. 3, Dez. 2018.
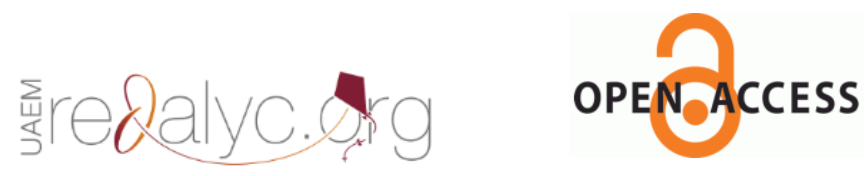


\section{Introdução}

A internacionalização da educação superior envolve a inserção de fatores internacionais, globais e interculturais nas atividades de ensino, pesquisa e extensão, representando um meio para diferentes ganhos institucionais, como por exemplo: a internacionalização curricular; o fortalecimento da produção científica; a aquisição de competências em línguas estrangeiras; a exposição a fatores multiculturais; e novas formas de captação de recursos financeiros (Rudzki, 2000; Paige, 2005). O fator internacional refere-se, estritamente, ao estabelecimento de relacionamentos entre nações, culturas e países, tendo em vista as demandas que a globalização provoca no processo de internacionalização; o fator intercultural abrange a administração de aspectos da diversidade cultural presentes nessas relações; e o fator global revela a estratégia para alcançar os objetivos no país-alvo (Knight, 2008).

Dentre as principais dimensões da internacionalização da educação superior destacam-se: mobilidade acadêmica (docente e discente), publicações em periódicos editados no exterior, projetos de pesquisa em conjunto com docentes estrangeiros, participação de docentes em grupos de pesquisa no país-alvo (Paige, 2005). Além dessas atividades citadas, acrescenta-se a internacionalização "em casa" (at home), que permite integrar os currículos com base no contexto global. Essa integração pressupõe explorar as competências dos docentes e técnicos na internacionalização dos currículos (Beelen, 2015). Como ressaltam Knight (2012), Leask, Hunter e Rumbley (2014) e Leal e Moraes (2017), a internacionalização do currículo tem se consolidado como fator essencial e estratégico das agendas de internacionalização dos organismos internacionais, dos governos e das instituições universitárias, sobretudo, nos países centrais.

De acordo com Hudzik (2011), os fatores que impulsionam o processo de internacionalização em casa estão relacionados, principalmente, ao aumento das condições de uma instituição universitária se internacionalizar sem necessidade de realizar atividades que exijam deslocamento físico aos países-alvo. Sendo assim, a inclusão dessa modalidade torna possível que as instituições de ensino (IEs) consigam realizar atividades desse tipo com custos mais baixos.

Nessa perspectiva e tendo em consideração a característica bilíngue dos cursos de Secretariado Executivo no Brasil, é relevante compreender as possibilidades de internacionalização para esses cursos. A internacionalização pode servir em três frentes para 
os cursos de SE: na academia, em que se amplia o conhecimento na área de estudo escolhida, nas relações interpessoais, assim como no aperfeiçoamento de um novo idioma. Ademais, os processos de comunicação e as transações internacionais fazem parte da formação acadêmica do secretariado executivo (Unioeste, 2017). Desse modo, entende-se que a mobilidade acadêmica também deva ser uma forma de capacitação, já que ela desenvolve competências diversas (como fluência em idioma e relacionamento interpessoal), capacitando os envolvidos no âmbito pessoal e profissional.

Dessa forma, o objetivo geral deste estudo é buscar possibilidades para ações de internacionalização entre o curso de Secretariado Executivo (SE) da Universidade Estadual do Oeste do Paraná (Unioeste) e aqueles localizados em países sul-americanos. Quanto ao objetivo específico, pretende-se identificar os cursos de graduação que se assemelham à nomenclatura e à matriz curricular de formação do profissional de SE. A delimitação deste estudo em abranger apenas países da América do Sul está relacionada com as teorias de internacionalização que consideram a "distância psíquica" como um fator preponderante quando uma organização decide ingressar no mercado internacional. Ou seja, por extensão, os países mais próximos à organização de interesse seriam seus prováveis destinos para o estabelecimento de relações internacionais (Lopes, 2015).

Este estudo se justifica por possibilitar mais oportunidades de parcerias internacionais aos cursos de SE na medida em que encontram cursos no exterior que se assemelham aos cursos brasileiros. Ademais, ao visualizar a possibilidade de cooperações, ampliam-se as reflexões sobre a estruturação do curso de Secretariado Executivo no Brasil em face à comparação internacional de matrizes curriculares, quanto às temáticas e à carga horária. Para isso, a internacionalização do currículo é uma das medidas que pode ser adotada para que essas oportunidades possam ser aproveitadas.

Entre as várias possibilidades de cursos de Secretariado Executivo no Brasil, escolheuse o da Unioeste, principalmente pelo fato de ser um dos cursos no Brasil que dispõe de uma quantidade significativa de professores graduados em SE com título de doutorado, o que colabora para a consolidação da cientificidade da área, necessária à verticalização dos cursos de SE (Maçaneiro \& Kühl, 2013).

Verticalização do ensino superior diz respeito à otimização da infraestrutura, do quadro docente e técnico e dos recursos da gestão das IEs, por meio da atuação dos docentes em diferentes níveis de ensino (Brasil, 2008). No caso específico do Secretariado Executivo da Unioeste, enseja-se criar um mestrado na área, tendo em vista o quadro docente da 
graduação e toda a estrutura que a Universidade já possui. Por se tratar de programa ainda, até o presente momento, inexistente no Brasil, todas as iniciativas que possam atender também os critérios da Capes (2017) (órgão julgador do mérito da proposição do Curso de Mestrado) colaboram nessa direção, tendo em vista que a internacionalização é um deles. Dessa forma, ao fortalecer o processo de internacionalização, ampliam-se as oportunidades de verticalização do curso de SE, uma vez que os órgãos de fomento, entre eles a Capes, avaliam a internacionalização nos processos de qualificação dos programas stricto sensu.

Salienta-se que o fenômeno da internacionalização é abordado neste estudo sob a perspectiva epistemológica funcionalista, buscando-se enfatizar aspectos pragmáticos relacionados a esse processo nas instituições de ensino investigadas. Entende-se que a internacionalização da educação superior envolve questões de natureza histórica, geopolítica, sociocultural, econômica, tecnológica e científica e é muito mais complexa do que a abordagem aqui desenvolvida, que se restringe a uma abordagem descritivo-exploratória inicial de um aspecto, porém relevante no sentido de conceber a internacionalização como um meio para fortalecer as atividades de ensino, pesquisa e extensão nas IEs. Nesse sentido, acredita-se que o curso de Secretariado Executivo tem muitas possibilidades de explorar e expandir suas atividades de internacionalização.

Quanto à organização deste artigo, além desta introdução, apresenta-se o referencial teórico sobre o conceito e as abordagens de internacionalização da educação superior, assim como a internacionalização do currículo e o conceito de internacionalização "em casa". Na sequência, constam a metodologia e os resultados da pesquisa coletados por meio de dados secundários. Por fim, apresentam-se as considerações finais e as perspectivas futuras rumo à internacionalização dos cursos de Secretariado Executivo.

\section{Referencial Teórico}

\section{Internacionalização da Educação Superior: principais conceitos}

A relação internacional entre as universidades acontece desde a Idade Média (séculos $\mathrm{V}-\mathrm{XV}$ ), quando estudantes e professores se deslocavam em busca dos centros de ensino de excelência. A expansão desse processo ocorre no período entre a $2^{\mathrm{a}}$ Guerra Mundial e o fim da "guerra fria" (Século XX), com o fortalecimento da Comunidade Europeia, a ascensão do 
Japão como potência econômica mundial e o acentuado processo de globalização (De Wit, 2002, Lima \& Contel, 2011).

No final do século XX e início do século XXI, o conceito de internacionalização passou a ser revisitado por diferentes pesquisadores que realizaram estudos em IEs, situadas na Europa, nos Estados Unidos da América e na América Latina. Destacam-se Altbach (2002), Knight (1994, 2004, 2008, 2012), De Wit (2002, 2011) e Van der Wende (1999, 2003).

Para Knight (1994), a percepção sobre internacionalização no ensino superior sofre mudanças impulsionadas, principalmente, pelos seguintes fatores: desenvolvimento de novas relações internacionais e consórcios; crescimento contínuo do número de estudantes, professores e pesquisadores em programas de mobilidade; aumento do interesse na inserção de conteúdo internacional e multicultural no currículo; novas políticas em âmbitos nacional e regional, direcionadas ao incentivo da educação internacional; entre outros.

O processo de internacionalização envolve diferentes dimensões, não se concentrando somente na mobilidade acadêmica. De fato, quando se fala em mobilidade acadêmica, a internacionalização não é um termo novo às universidades; no entanto, ao passar dos anos precisou atender às demandas da globalização. Segundo Paige (2005), a internacionalização antecede a globalização no âmbito das universidades, representando termos distintos. Enquanto a globalização se relaciona a fatores que afetam o mundo como um todo, a internacionalização exerce influência diretamente nas organizações e instituições.

É necessário ressaltar que o processo de globalização foi fortalecido pela existência de um discurso político e ideológico que submeteu diferentes esferas das ações humanas aos interesses da economia global causando diferentes impactos como, por exemplo, a mercadorização da educação (Altbach, 2002, Santos, 2011, Leite \& Genro, 2012). Nesse sentido, Morosini (2006) destaca que, entre os desafios da relação entre internacionalização da educação superior e globalização, há que considerar os efeitos de negociações regulatórias que não levam em conta características regionais e a soberania do estado-nação.

Para além dos desafios que a globalização oferece ao processo de internacionalização, cabe esclarecer o significado de internacionalização na educação superior. Segundo Knight (2004), a internacionalização é um processo que ocorre nos níveis nacional, setorial e institucional, buscando integrar fatores de natureza internacional, intercultural e global às políticas e aos programas que garantam sustentabilidade e centralidade na definição da missão e dos valores da instituição. 
Outro conceito é apresentado por Altbach, Reisberg e Rumbley (2009), em um relatório preparado para a Conferência Mundial da Unesco sobre Educação Superior, realizado em 2009, em que a internacionalização é definida como a variedade de políticas e de programas que as universidades e os governantes operacionalizam em resposta à globalização. Alguns exemplos dessas práticas são: envio de estudantes para estudar no exterior, a criação de um campus no exterior ou alguma parceria internacional.

Para além da mobilidade, a internacionalização está crescendo em importância na educação superior, motivada, dentre outros fatores, pelas atividades domésticas associadas à integração de competências interculturais e multiculturais e às atividades institucionais, sem a necessidade de sair do país. Essa dimensão está relacionada ao conceito de internacionalização "em casa":

[...] a internationalization at home é a integração intencional de fatores internacionais e interculturais no currículo formal e informal que alcance todos os alunos, dentro de ambientes de aprendizagem domésticos. Para tanto, o conceito de internacionalização abrange a inclusão de tipos alternativos de mobilidade, como é o caso da mobilidade virtual; integração de competências dos docentes e técnicos na internacionalização de currículos e; avaliação dos resultados da aprendizagem de discentes/docentes nessas atividades (Beelen, 2015, p. 13, tradução nossa).

Nessa perspectiva, como ressalta Hudzki (2011), a internacionalização deve ser concebida como um processo abrangente (“comprehensive internationalization”), que envolve o comprometimento tanto de discentes/docentes quanto de funcionários técnicoadministrativos da universidade (Knight, 1994, 2004, 2008, De Wit, 2002, Beelen, 2015).

De acordo com De Wit (2002), que aprofundou sua pesquisa nos Estados Unidos e em países da Europa, as razões para a internacionalização da educação superior podem ser divididas em quatro grandes grupos: socioculturais, acadêmicas/institucionais, políticas e econômicas. As razões socioculturais estão condicionadas à natureza dos diferentes países, mas, em geral, a internacionalização representa um meio para a conscientização de que é necessário haver uma relação de interdependência entre as pessoas e as sociedades de forma a conviver com os fatores interculturais envolvidos no processo. Quanto às razões acadêmicas/institucionais, salienta-se que a internacionalização representa um meio para promover, junto à comunidade acadêmica, as habilidades de conhecer, apreciar e articular os fatores que advêm da interdependência entre as nações. Já as razões políticas estão relacionadas ao estabelecimento de parcerias como uma forma de investimento diplomático para futuras relações políticas. Finalmente, as razões econômicas concentram-se nos ganhos 
financeiros que podem ser obtidos por meio da internacionalização da educação superior, principalmente quanto ao desenvolvimento tecnológico e ao desenvolvimento econômico.

\section{Internacionalização: teorias aplicadas à educação superior}

Os primeiros estudiosos de países centrais de internacionalização da educação superior foram Hans De Wit, Jane Knight e Philip Altbach, com publicações iniciadas entre os anos de 1994 e 1997, abrangendo Europa, Estados Unidos, Canadá e Austrália. Em geral, suas abordagens visualizam a internacionalização como um ciclo contínuo, constituído de diferentes etapas, que integrarão dimensões internacionais, interculturais e globais ao sistema de ensino superior. Para tanto, foram definidas quatro abordagens que poderão dar suporte às instituições de ensino superior no estabelecimento de estratégias de internacionalização, conforme o Quadro 1:

Quadro 1- Diferentes abordagens sobre a internacionalização da educação superior.

\begin{tabular}{|c|l|}
\hline \multicolumn{1}{|c|}{ Abordagem } & \multicolumn{1}{c|}{ Descrição } \\
\hline Abordagem do processo ou estratégia & $\begin{array}{l}\text { A internacionalização é realizada por meio da integração } \\
\text { da dimensão internacional às principais atividades e } \\
\text { políticas da instituição (ensino, pesquisa e extensão). } \\
\text { Alguns termos que caracterizam esse processo são: } \\
\text { inspirar, integrar, incorporar e permear. }\end{array}$ \\
\hline Abordagem baseada em atividades & $\begin{array}{l}\text { A internacionalização é caracterizada por tipos de } \\
\text { atividades específicos como, por exemplo, currículo, } \\
\text { intercâmbio de estudantes e cooperação técnica. }\end{array}$ \\
\hline Abordagem baseada em competências & $\begin{array}{l}\text { A internacionalização é caracterizada pela valorização da } \\
\text { dimensão humana em relação ao desenvolvimento de } \\
\text { novas habilidades, atitudes e aquisição de conhecimento } \\
\text { por parte dos estudantes, corpo docente e de técnicos. }\end{array}$ \\
\hline Abordagem cultural (ethos approach) & $\begin{array}{l}\text { A internacionalização é definida de acordo com } \\
\text { propósitos específicos relacionados aos resultados } \\
\text { esperados. Além disso, se caracteriza } \\
\text { pelo } \\
\text { desenvolvimento de uma cultura organizacional (valores, } \\
\text { normas, crenças) que valoriza e dá suporte às iniciativas } \\
\text { interculturais e internacionais. }\end{array}$ \\
\hline
\end{tabular}

Fonte: As autoras com base em De Wit (2002) e Knight (2004).

Ressalta-se que essas abordagens não são mutuamente exclusivas. Sendo assim, a presença de uma liderança, ao conceber um modelo de internacionalização, torna-se essencial para atender às particularidades de cada instituição de ensino superior. De acordo com Hudzik (2011), o conceito de internacionalização tem seu significado baseado no compromisso institucional voltado ao estabelecimento de ações que fomentem a inclusão de fatores internacionais e interculturais em todas as atividades de ensino, pesquisa e extensão. Nesse sentido, devem ser promovidos valores institucionais de tal maneira que possam ser 
assumidos pela liderança da instituição como um todo. Além disso, deve ocorrer sempre a promoção desses valores institucionais em relação à internacionalização, aos discentes, aos docentes e aos técnicos.

Quanto ao perfil do gestor envolvido no processo de internacionalização, ressalta-se o estudo de Leal, Céspedes e Stallivieri (2017), ao enfatizar que a internacionalização demanda mudanças operacionais, estruturais e pragmáticas nas instituições envolvidas, portanto, é essencial conhecer o perfil dos gestores para apoiar adequadamente esse processo.

Ainda sobre os modelos de internacionalização da educação superior apresentandos no Quadro 1, é possível analisá-los sob a luz de teorias da internacionalização que explicam o comportamento das empresas ao escolher um país-alvo (Vigorena, 2017). Uma das teorias sobre a internacionalização de empresas é a que preconiza o conceito de "distância psíquica". Embora na década de 1960 já houvesse menção desse termo (Lopes, 2015), foi na década de 1970, por meio dos artigos de autores da Escola de UppSala (Johanson \& Vahlne, especialmente), que esse conceito ganhou corpo e foi disseminado.

Uma das principais teses desses autores era que, ao buscar a internacionalização, as empresas, inicialmente, buscavam estabelecer negócios entre países entre os quais houvesse menor distância psíquica para, gradualmente, conforme adquirissem conhecimento, irem aumentando a relação com países de maior distância psíquica (Johanson \& WiedersheimPaul, 1975; Johanson \& Vahlne, 1977, 2013). Ou seja, os gestores das empresas de determinado país procuram negociar com países em que percebem menos diferenças linguísticas, culturais, de estrutura governamental e de desenvolvimento industrial.

Como pode ser observado, a teoria da distância psíquica foi elaborada e teve inspiração nas teorias de internacionalização de empresas. No entanto, embora ainda pouco frequente na literatura (Borges \& Amal, 2016), pode-se também pensar essa dinâmica em relação à internacionalização nas IEs. Por extensão, supõe-se que a internacionalização nas IEs pode acontecer inicialmente com países que tenham menor distância psíquica com o Brasil. Nesse caso, países que tivessem o mesmo idioma ou idioma bastante similar, fossem mais próximos geograficamente, e mais próximos em relação à sua cultura, ou seja, países em que se compartilhassem valores, crenças e costumes.

Dessa forma, ao se relacionar países que cumprissem os requisitos supracitados e, por conseguinte, serem considerados de menor distância psíquica, entendeu-se que os países da América do Sul seriam ideais para se iniciar o processo de internacionalização nas IEs do Brasil. Isso se deve ao fato de que, além da menor distância geográfica, a semelhança entre as 
línguas portuguesa e espanhola, ambas oriundas da mesma origem do latim vulgar (Ilari, 2006), facilitam o processo de implantação da internacionalização, seja "em casa" ou via mobilidade acadêmica tradicional.

\title{
A internacionalização do currículo
}

Moreira e Candau (2007) afirmam que a palavra currículo deriva dos diversos modos como a educação é concebida historicamente à luz das mais diversas teorias. De maneira geral, os entendimentos sobre o que é currículo são:

\begin{abstract}
a) os conteúdos a serem ensinados e aprendidos; b) as experiências escolares de aprendizagem a serem vividas pelos alunos; c) os planos pedagógicos elaboradores por professores, escolas e sistemas educacionais; d) os objetivos a serem alcançados por meio de processo de ensino; e) os processos de avaliação que terminam por influir nos conteúdos e nos procedimentos selecionados nos diferentes graus da escolarização (Moreira \& Candau, 2007, p.18).
\end{abstract}

Tendo em conta a importância do currículo na formação do aluno, é fundamental que o desenho curricular seja constantemente revisado com vistas a acompanhar as mudanças sociais e culturais que influenciam esse processo, demandadas, principalmente, pela globalização e disseminação dos meios de comunicação e informação. Uma dessas exigências contemporâneas é a internacionalização dos currículos. Conforme Beelen (2015), a internacionalização do currículo é uma atividade contemplada na internacionalização "em casa", a qual preconiza que se utilizem os meios de comunicação e informação, tornando possível a interação a distância, tais como as ferramentas Skype ou videoconferência. Isso significa a possibilidade de se planejar um currículo mais flexível à mobilidade acadêmica, ao mesmo tempo que permita inserir elementos globais, internacionais e interculturais na formação dos alunos como um todo. Algumas recomendações apresentadas por essa autora sobre o planejamento de ações estratégicas relacionadas à internacionalização "em casa" são:

a) a implementação necessita de uma abordagem sistemática, a fim de romper com alguns conceitos existentes sobre os processos de ensino e aprendizagem;

b) a internacionalização do currículo poderá exigir novos tipos de liderança e de gestão do processo de internacionalização;

c) elaboração de estratégias para aumentar o envolvimento dos docentes no processo de internacionalização; 
d) há necessidade de avaliar até que ponto as universidades e os programas, em particular, têm articulado as competências exigidas no currículo com as exigências da prática profissional, pois somente com essas informações será possível incluir a dimensão internacional;

e) a competência em línguas estrangeiras, principalmente o inglês, deve ser um objetivo instituticional de alcance aos discentes, docentes e técnicos.

Com isso, é possível perceber a amplitude dos desafios que necessitam ser superados à internacionalização do currículo. Segundo Moreira e Silva (1994), o currículo é um campo de criação cultural e simbólica, espaço para a formação de significado e significação. Nele, os contéudos são confrontados como em um campo de batalha, pois são de natureza conflitante e ambígua. Não existe uma cultura universal mais fundamentada para ser transmitida, senão, o conhecimento a ser compartilhado e negociado. Nessa tendência, o currículo que atenda a essas ambições, principalmente as das chamadas universidades de países de periferia, seria aquele configurado como um espaço de produção cultural, em que os recursos existentes funcionam como matéria-prima da invenção, recreação, especialmente de contestação e transgressão.

No caso brasileiro, certas medidas políticas foram tomadas, mesmo que ainda estejam em um nível documental, sinalizam alguma mobilização para que as instituições de ensino superior abracem o apelo global para a internacionalização e, ao mesmo tempo, deem respostas às necessidades e aspirações locais (Sacristán, 2002). Nesse sentido, o curso de Secretariado Executivo no Brasil deve obter conhecimento sobre como ele é concebido no exterior, buscando ampliar as possibilidades de inserção de fatores globais, internacionais e interculturais na concepção da matriz curricular.

Certamente, quando se fala em internacionalização da educação superior, há necessidade de considerar as questões históricas relacionadas ao processo de avaliação das instituições. Segundo Leite e Genro (2012), o processo de avaliação das instituições de educação superior da América Latina e Caribe foram reformadas em 1990 e cujas propostas surgiram em uma vertente utilitarista que colocou as IEs na rota dos processos de globalização neoliberal. Essa visão utilitarista continua nos dias atuais como, por exemplo, na existência de "[..] estudos que buscam tornar os currículos latino-americanos assemelhados aos europeus de modo a favorecer, teoricamente, o intercâmbio e a mobilidade discente - a partir da introdução das competências curriculares em carreiras de formação universitária" 
(Leite \& Genro, 2012, p. 772). Sob essa perspectiva, a internacionalização da educação não deve ser tratada como algo incondicionalmente positivo às instituições de ensino. Reforça-se a necessidade de avaliar aspectos relacionados às suas especificidades regionais e locais e às suas missões fundamentais, de forma a entender suas implicações nesse processo. A interação entre fatores globais e locais podem gerar resultados mais significativos para as atividades de internacionalização.

\section{Metodologia}

Este estudo é qualitativo, de natureza descritivo-exploratória e é orientado pela estratégia do estudo comparativo. Segundo Yin (2015), nos estudos comparativos, os casos são vistos como configurações ou combinação de características. Neste estudo, a escolha dos casos ocorreu justamente pela compatibilidade de características.

Segundo Feilzer (2010), além de indicar os métodos escolhidos na pesquisa, é importante posicionar-se em relação às escolhas epistemológicas dos pesquisadores. Assim, para este estudo adota-se uma perspectiva epistemológica funcionalista que leva em conta o pragmatismo ao oferecer uma visão de mundo focada nas consequências da pesquisa para a efetivação do problema a ser pesquisado. Isto é, embora haja toda uma discussão em torno de questões sociológicas e políticas quanto à internacionalização, por exemplo, opta-se por abordar a funcionalidade do processo.

A coleta de dados foi realizada por meio de fontes secundárias e ocorreu durante os meses de maio e junho de 2017, com o objetivo de buscar possibilidades para ações de internacionalização junto às universidades de países sul-americanos em cursos de graduação que se assemelhassem ao Curso de Secretariado Executivo da Unioeste.

Os países-alvo desta pesquisa incluíram: Argentina, Bolívia, Chile, Colômbia, Equador, Paraguai, Peru, Venezuela e Uruguai. As Guianas e o Suriname não foram incluídos nesta pesquisa por não se adequarem na teoria da distância psíquica.

Assim, com o propósito de direcionar a busca para os cursos na área e considerando que a consulta por meio de buscadores na internet, dentre eles o Google de cada país-alvo, agilizaria essa etapa da pesquisa, buscou-se o termo "Secretariado Ejecutivo", em língua espanhola, já que essa é a língua predominante na América do Sul. Do mesmo modo, incluíram-se buscas nos sites dos ministérios da educação dos países investigados. 
Após essa primeira seleção em cada país mencionado, buscou-se, por meio das websites das universidades investigadas em que os cursos foram identificados, a equivalência em relação à titulação de bacharelado, com duração proporcional de quatro anos, bem como matriz curricular semelhante ou equivalente. Em uma fase posterior, investigaramse cursos técnicos e tecnológicos devido às especificidades apresentadas por eles nesses países, consideradas relevantes para complementar as análises empreendidas.

Após a identificação dos cursos por meio da pesquisa documental, procedeu-se à tradução e à análise sistemática da matriz curricular do curso estrangeiro compatível, conforme a teoria apresentada. Nessa fase, para mais esclarecimentos quanto ao conteúdo programático, entrou-se em contato telefônico com a coordenadora do curso investigado.

\section{Análise e Discussão dos Resultados}

A pesquisa, realizada junto às IEs, que serão apresentadas no Quadro 2 teve como objetivo analisar a composição da matriz curricular para avaliação de possibilidades de mobilidade acadêmica. Este seria um passo inicial, para mais adiante, se ampliarem as atividades de internacionalização em parceria com o curso de SE da Unioeste. É importante esclarecer que os cursos técnicos também foram registrados nesta investigação, pois nos países citados os alunos têm a opção de seguir estudando por mais um ou dois anos e, assim, obterem o nível superior. Isso é possível, uma vez que esses países adotam o sistema de créditos acadêmicos que permite o aproveitamento de conteúdos em todos os níveis de estudo. De acordo com Restrepo (2005), o sistema de créditos acadêmicos permite maior sequencialidade e mobilidade entre os distintos níveis da educação superior e entre diferentes IEs, facilitando, assim, o reconhecimento de saberes e a equivalência de títulos.

A unidade de créditos utilizada pelas universidades no mundo todo é um sistema variável que pode estar relacionada a diferentes parâmetros, tais como as horas de aulas atendidas, carga horária de trabalho independente, ou mesmo o desempenho acadêmico apresentado. Entender como um sistema de créditos funciona é fundamental, pois por meio desse dado é possível avaliar e medir a trajetória acadêmica de um estudante, dando-lhe a oportunidade de transferir seus créditos para o aproveitamento de estudos entre diferentes cursos e universidades.

Nos países pesquisados (Argentina, Bolívia, Colômbia, Chile, Equador, Paraguai, Peru, Uruguai e Venezuela), um crédito acadêmico equivale a 48 horas de trabalho - nelas se 
incluem todas as atividades exigidas do estudante para que se alcance as metas de aprendizado. Ou seja, dentro dessa carga horária estão as aulas presencias com o acompanhamento docente e as demais horas despendidas e necessárias para seu estudo complementar, prática e preparação para exames.

De forma geral, em cursos mais tradicionais, uma unidade de crédito implica uma aula atendida e outras duas horas de estudos autônomas. Embora haja uma unidade de medida para o crédito, as horas de trabalho de um estudante estarão submetidas ao número de semanas do período letivo, que está também ligada às características e à natureza do curso. Suponha-se que um semestre possua 16 semanas, portanto um crédito (48/16) resultará em três horas semanais de dedicação por parte do aluno, dais quais, uma será presencial e duas de trabalho independente (Restrepo, 2005).

A seguir, o Quadro 2 apresenta os cursos de SE encontrados em cada um dos países selecionados, apontando seus respectivos níveis de estudo e nomenclaturas. Cabe destacar que as designações "Tecnicatura", "Tecnología" e "Técnico Universitario/Superior" referem-se a cursos de nível médio, de acordo com resoluções específicas do Ministério da Educação dos países investigados (Restrepo, 2005).

Quadro 2- Cursos de Secretariado Executivo nos países sul-americanos selecionados.

\begin{tabular}{|c|c|c|}
\hline Países & Ensino Superior & Técnicos $\mathrm{e}^{*}$ tecnológicos \\
\hline Argentina & Não encontrado & $\begin{array}{l}\text { - Tecnicatura Universitaria en Secretariado Ejecutivo } \\
\text { Universidad Católica de Salta } \\
\text { - Tecnicatura en Organización de Eventos - Universidad de Morón } \\
\text { - Tecnicatura Universitario en Ceremonial y Protocolo - Universidad } \\
\text { Católica de Salto } \\
\text { - Tecnicatura en Organización de Eventos - Universidad Argentina } \\
\text { John F. Kennedy } \\
\text { - Técnico en Ceremonial - Universidad del Aconcagua }\end{array}$ \\
\hline Bolívia & Não encontrado & • Não encontrado \\
\hline Colômbia & Não encontrado & $\begin{array}{l}\text { - Tecnología en Asistencia Gerencial - Universidad Colegio Mayor } \\
\text { de Cundinamarca } \\
\text { - Tecnología en Organización de Eventos - Politécnico Colombiano } \\
\text { Jaime Isaza Cadavid } \\
\text { - Técnico Laboral en Auxiliar Administrativo Bilingüe - Corporación } \\
\text { Politécnico Marco Fidel Suarez } \\
\text { Técnico Profesional en Secretariado Bilingüe - Politécnico Colombo } \\
\text { Andino }\end{array}$ \\
\hline Chile & Não encontrado & $\begin{array}{l}\text { - Dirección y Producción de Eventos -Universidad del Pacifico } \\
\text { - Técnico de Nivel Superior en Organización y Producción de Eventos } \\
\text { - Universidad de las Américas } \\
\text { Secretariado Ejecutivo Gerencial - Centro de Formación Técnica de } \\
\text { la Universidad de Valparaíso }\end{array}$ \\
\hline Equador & $\begin{array}{l}\text {-Secretariado Ejecutivo } \\
\text {-Secretariado Ejecutivo }\end{array}$ & • Não encontrado \\
\hline
\end{tabular}


Vigorena, D. A. L., Bernardon, M., Battisti, P. S. S., Barcellos, C. A. (2018)

\begin{tabular}{|c|c|c|}
\hline & $\begin{array}{l}\text { Bilingüie - Universidad } \\
\text { Laica Eloy Alfaro de } \\
\text { Manabí } \\
\text { Secretariador Ejecutivo } \\
\text { Gerencial - Universidad } \\
\text { de Cotopaxi }\end{array}$ & \\
\hline Paraguai & Não encontrado & - Não encontrado \\
\hline Peru & Não encontrado & $\begin{array}{l}\text { - Técnico en Secretariado Ejecutivo } \\
\text { - Instituto Superior Sise } \\
\text { - Cima's Instituto de Educación Superior Tecnológico Privado } \\
\text { - Instituto Superior Tecnológico Latino } \\
\text { - Instituto de Educación Superior Telesup } \\
\text { - Técnico en Secretariado Ejecutivo Computadorizado - Instituto } \\
\text { Superior Tecnológico CESCA }\end{array}$ \\
\hline Uruguai & Não encontrado & $\begin{array}{l}\text { - Tecnicatura en Secretariado Ejecutivo - Instituto Metodista } \\
\text { Universitario Crandon } \\
\text { - Tecnicatura en Asistente Ejecutivo - Instituto Metodista } \\
\text { Universitario Crandon }\end{array}$ \\
\hline Venezuela & Não encontrado & $\begin{array}{l}\text { - Técnico Superior en Secretariado Administrativo - Colegio } \\
\text { Universitario Monseñor de Talavera }\end{array}$ \\
\hline
\end{tabular}

Fonte: as autoras (2017)

*Os cursos técnicos e tecnológicos foram agrupados porque em alguns países os cursos tecnológicos não são considerados de nível superior. Podem ser cursos pré-universitários, visando ao posterior aproveitamento de créditos cursados por parte de alunos que queiram estudar cursos de bacharelado ou licenciatura.

De acordo com o Quadro 2, constata-se que, na maioria dos países sul-americanos investigados, o curso de SE é ofertado predominantemente nos níveis tecnológico e técnico. Ressalta-se que esses cursos representam um ponto de partida para que um estudante inicie sua formação profissional em SE e depois consiga continuar se quiser obter bacharelado ou licenciatura em outras áreas, devido às vantagens oferecidas pelo aproveitamento de créditos. Ou seja, há possibilidade de validar alguns créditos obtidos em cursos de nível médio, dependendo da compatibilidade com a área escolhida pelo aluno no ensino superior.

Apenas no Equador foram localizados cursos de SE, em nível superior, que outorgam o título de bacharelado. Um deles é ofertado por uma universidade privada "Universidad de Cotopaxi”, localizada na cidade de Latacunga (capital do Estado de Cotopaxi). O outro curso é ofertado por uma universidade pública "Universidad Laica Eloy Alfaro de Manabî" (Uleam), na cidade de Manta (Estado de Manabí), umas das cinco principais cidades do país.

Com o intuito de prosseguir com a análise em relação às matrizes curriculares, optouse por comparar o curso da Uleam "Secretariado Ejecutivo/Secretariado Ejecutivo Bilingüe" com o curso de Secretariado Executivo da Unioeste. A justificativa inicial deu-se devido ao fato de o curso da Uleam receber a nomenclatura "Secretariado Ejecutivo", equivalente à nomenclatura do curso que é ofertado no Brasil. Além disso, a comparação entre essas 
matrizes curriculares é pertinente tendo em vista que ambos os cursos são públicos e possuem ao menos 30 anos de funcionamento. Essa é uma justificativa adicional, a mobilidade discente é facilitada já que não haverá cobrança de mensalidade, o que por muitas vezes é um complicador quando a contrapartida do intercâmbio para a IEs públicas requer o pagamento da mensalidade nas IEs privadas.

Cabe enfatizar que um resultado inesperado foi descoberto: encontrou-se um curso de graduação com conteúdos muito próximos à matriz curricular do Secretariado Executivo, mas com nomenclatura distinta. É o curso de Engenharia Comercial, ofertado no Chile em diferentes instituições de ensino. Neste curso são ofertadas disciplinas da área de administração, tais como marketing, gestão de pessoas, estratégia, dentre outras; e da área de comunicação abrangendo o ensino de idiomas. No entanto, não há disciplinas relacionadas especificamente às técnicas secretariais.

\section{Comparação de matrizes curriculares: Brasil X Equador}

O curso de SE da "Universidad Laica Eloy Alfaro de Manabî" (Uleam) foi criado em 1975, de natureza pública, com o principal objetivo de estimular as atividades econômicas do setor, entregando ao mercado de trabalho secretários executivos com formação técnica de três anos. No entanto, o perfil do secretário executivo foi remodelado pela Faculdade de Ciência da Educação, no período de 1980 a 1981, acrescentando-lhe mais dois anos de estudos. Os estudantes concluintes do terceiro, quarto e quinto ano, recebiam os títulos de Secretário Executivo, Professor de Ensino Médio e Licenciado em Ciências da Educação com especialidade na área secretarial, respectivamente (Uleam, 2017).

Já no ano de 1985, considerada a criação do curso de fato, a sua formatação foi revista e retoma-se a modalidade inicial, ou seja, o título de Secretariado Executivo, com duração de três anos, aderindo-se à Faculdade de Ciências Administrativas, área afim e razão de sua criação. O currículo do curso foi reconhecido em 1986 (Uleam, 2017).

No ano de 1990, foi apresentado um projeto que aumentasse os estudos para mais dois anos, a fim de transformá-lo em um curso superior, conferindo o título de Bacharelado (Licenciado, termo usado em espanhol) em Secretariado Executivo, totalizando cinco anos de estudo. Porém, em 1998, por disposições legais, a formação é reduzida para quatro anos. No período letivo de 2000 a 2001 houve uma reforma acadêmica e novas disciplinas foram incorporadas seguindo as tendências do mercado de trabalho (Uleam, 2017). 
A partir do ano de 2004 foi criada a graduação em Secretariado Ejecutivo Bilingüe, sanando uma demanda do setor por um profissional que fosse capaz de atender às empresas no mais amplo âmbito, comunicando-se de forma eficiente nos idiomas: espanhol e inglês. Dessa forma, atualmente, ambos os cursos, Secretariado Ejecutivo e Secretariado Ejecutivo Bilingüe são ofertados de forma independente, pois há uma matriz curricular distinta para cada curso. As disciplinas são semestrais e a conclusão do curso ocorre em oito semestres (quatro anos), outorgando ao estudante o grau de "Licenciado en Secretariado Ejecutivo" ou "Licenciado en Secretariado Ejecutivo Bilingüe", o que equivale no Brasil ao grau de bacharelado (Uleam, 2017).

Quanto ao curso de SE da Unioeste, a sua concepção ocorreu na década de 1980, de natureza pública, na cidade de Toledo/PR - Brasil. Com o crescente surgimento de empresas comunitárias na cidade de Toledo- PR, uma nova demanda por profissionais que suprissem as exigências e necessidades desse setor, impulsionou a criação do curso em 1986 e a oferta de vestibular em 1987. Assim, o curso comemorou, em 2017, trinta anos de existência (Unioeste, 2017).

O foco inicial do curso concentrava-se na oferta de disciplinas da área de comunicação, pois o curso estava vinculado à Faculdade de Ciências Humanas. No entanto, atendendo às mudanças na própria concepção das IEs e às novas demandas do mercado de trabalho, a matriz curricular foi alterada ao longo dos anos e o perfil do futuro profissional também adquiriu novos contornos. Assim, em 2005, a ênfase do curso se voltou para as áreas secretariais, comunicacionais e administrativas e a matriz curricular foi alterada na época (Unioeste, 2017).

O curso é anual, mas houve, em 2016, uma outra alteração na matriz curricular de forma que as disciplinas atendessem às demandas pela formação de um profissional com competências globais e interculturais para atuar em contextos diversos. Ressalta-se que no momento de sua implantação, em 2017, poucas disciplinas foram semestralizadas e a grande maioria ainda é ofertada anualmente. A formação regular do estudante é concluída em quatro anos, conferindo-lhe o título de Bacharel em Secretariado Executivo (Unioeste, 2017).

Após explicadas algumas características dos cursos investigados, será realizada a comparação entre as matrizes curriculares, por áreas de oferta. A divisão de áreas foi definida de acordo com o Projeto Político Pedagógico do curso de SE da Unioeste. Para tanto, o agrupamento das disciplinas do curso da Uleam foi realizado com base nessa separação, com vistas a facilitar a comparação entre as duas matrizes curriculares. Para iniciar essa etapa, 
apresenta-se o Quadro 3, concentrando-se nas disciplinas da área de Administração, quanto às temáticas e carga horária. Salienta-se que a carga horária do Equador é dada em créditos. Desse modo, converteu-se em horas para tornar-se mais fácil a visualização. A principal justificativa para isso é a diferença na contagem de horas-aula no Brasil em relação ao Sistema de Créditos Acadêmicos adotado pelas instituições dos países investigados.

Quadro 3 - Comparativo da matriz curricular do Secretariado Executivo: Área Administração- Brasil x Equador.

\begin{tabular}{|c|c|}
\hline $\begin{array}{c}\text { Disciplina área Administração } \\
\text { Unioeste-Brasil }\end{array}$ & $\begin{array}{l}\text { Disciplina área Administração } \\
\text { Uleam - Equador }\end{array}$ \\
\hline Administração de Empresas (136h) & Administração (128h) \\
\hline Princípios da Administração (68h) & Contabilidade Básica (64h) \\
\hline Contabilidade $(68 \mathrm{~h})$ & Contabilidade Computadorizada (128h) \\
\hline Matemática Financeira (68h) & Matemática Financeira (128h) \\
\hline Marketing (68h) & Matemática Básica (64h) \\
\hline Administração de Recursos Humanos (68h) & Marketing (128h/192h) \\
\hline Direito Organizacional (68h) & Gestão de Projetos (128h) \\
\hline Economia de Empresas (68h) & Desenvolvimento Humano $(64 \mathrm{~h} / 128 \mathrm{~h})$ \\
\hline Estratégia Empresarial (68h) & $*$ Direito do trabalho $(128 \mathrm{~h})$ \\
\hline \multirow{10}{*}{ Empreendedorismo (68h) } & *Qualidade Total (128h) \\
\hline & *Projeto de Marketing (64h) \\
\hline & *Comércio Exterior (128h) \\
\hline & *Cultura Organizacional $(128 \mathrm{~h})$ \\
\hline & $* *$ Cultura e ambiente $(128 \mathrm{~h})$ \\
\hline & **Gestão de Pessoas (192h) \\
\hline & **Economy to Trade $(128 \mathrm{~h}) ;$ - ministrada em inglês \\
\hline & **International Trade (192h); - ministrada em inglês \\
\hline & Estatística $(128 \mathrm{~h} / 64 \mathrm{~h})$ \\
\hline & *Tributação (192h) \\
\hline
\end{tabular}

Fonte: as autoras (2017)

*Disciplinas ministradas exclusivamente no Curso de Secretariado Ejecutivo.

** Disciplinas ministradas exclusivamente no Curso de Secretariado Ejecutivo Bilingüe.

O Quadro 3 mostra que as temáticas das disciplinas do curso de SE da Unioeste, no tocante à área de administração, são amplamente contempladas na matriz do curso da Uleam, com exceção da disciplina de empreendedorismo. Pelo material documental disponível no site era impossível saber se mesmo não havendo a disciplina com o nome "empreendedorismo", esse conteúdo não fizesse parte do conteúdo programático de uma outra disciplina. Assim, por meio de ligação telefônica, a coordenadora do Curso da Uleam confirmou que não há o conteúdo de Empreendedorismo em nenhuma disciplina do curso de Secretariado Ejecutivo ou do curso de Secretariado Ejecutivo Bilingüe.

Por outro lado, verifica-se que a disciplina de Comércio Exterior não consta na matriz do curso da Unioeste. Ao total são três disciplinas relacionadas ao comércio exterior, sendo que duas são ministradas em inglês e exclusivamente pertencentes ao curso de Secretariado Ejecutivo Bilingüe da Uleam. 
Observa-se também que analisar a carga horária das disciplinas e compará-las torna-se um processo complexo, devido às características do sistema de créditos adotado pela Uleam, que prevê duas horas de trabalho complementares por parte do aluno para cada hora presencial com o docente. Dessa forma, quando isolada a quantidade de horas em sala da disciplina de Matemática Financeira do curso da Unioeste, por exemplo, as 68h administradas presencialmente são superiores às $128 \mathrm{~h}$ da Uleam, pois nesta matriz aproximadamente 46 horas seriam presenciais e as outras $82 \mathrm{~h}$ relacionadas ao trabalho independente dos alunos.

Esses resultados corroboram a necessidade de existir uma flexibilização na validação de horas estudadas sejam elas em formato de créditos ou não. Assim, mesmo que se encontrem cursos similares, ainda assim dificilmente a carga horária será semelhante, o que reforça discussões nesse sentido, como no caso do Programa do Ciências sem Fronteiras $(\mathrm{CsF})$ em que se relatava situação parecida antes da extinção dos programas destinados à graduação, em 2017.

Em 2016, foram veiculadas na mídia as palavras do então Ministro da Educação sobre o CsF para justificar, inclusive, a extinção do programa: "Havia também o problema da não equivalência de disciplinas entre os cursos de outros países e os do Brasil. Isso tornava o ano acadêmico internacional muitas vezes inaproveitável para efeitos curriculares[...]" (Rodrigues, 2016). Da mesma forma, essa dificuldade foi também retratada na academia. Confira, por exemplo, Aveiro (2014) quando afirma que o reconhecimento dos créditos foi outro aspecto problemático no CsF e critica o sistema de forma geral sugerindo uma simplificação na revalidação dos diplomas.

Na sequência, o Quadro 4 apresenta o comparativo da matriz curricular do SE da Unioeste: Área Secretarial - Brasil x Equador. 
Quadro 4 - Comparativo da matriz curricular do Secretariado Executivo: Área Secretarial- Brasil x Equador.

\begin{tabular}{|l|l|}
\hline \multicolumn{1}{|c|}{$\begin{array}{c}\text { Disciplina área Secretarial } \\
\text { Unioeste - Brasil }\end{array}$} & \multicolumn{1}{c|}{$\begin{array}{c}\text { Disciplina área Secretarial } \\
\text { Uleam - Equador }\end{array}$} \\
\hline Assessoria e Consultoria Empresarial (136h) & Técnicas de Secretariado (128h) \\
Técnicas de Secretariado Executivo (68h) & Ética Profissional (128h/64h) \\
Comunicação Organizacional I e II (136h) & Estudos de Gênero (128h) \\
Ética Profissional e Responsabilidade & Ecologia (64h) \\
Socioambiental (68h) & Comportamento Secretarial (128h) \\
Gestão Secretarial (136h) & *Etiqueta e Protocolo (128h) \\
Fundamentos de Secretariado Executivo (68h) & * Administração de documentos (128h) \\
Gestão de Eventos (68 h) & **Events Organization (64h) - em inglês \\
Gestão de Documentos (68h) & Gestão de dados básicos (128h) \\
Recursos Tecnológicos Aplicados ao Secretariado & Gestão de dados relacionais - SQP (128h) \\
Executivo (68h). & Informática Básica (128h/64h) \\
& Informática Intermediária (128h) \\
& Informática Avançada (128h) \\
& Sistemas de informação intermediários (128h) \\
& Sistemas de informação avançados (128h) \\
& Sistema de Arquivo (128h) \\
& Procedimento Parlamentar (64h/128h) \\
& Workshops de Rotinas de Escritório (128h). \\
\hline
\end{tabular}

Fonte: as autoras (2017)

*Disciplinas ministradas exclusivamente no Curso de Secretariado Ejecutivo.

** Disciplinas ministradas exclusivamente no Curso de Secretariado Ejecutivo Bilingüe.

$\mathrm{Na}$ área secretarial, de forma geral, há disciplinas compatíveis entre a matriz curricular do curso da Unioeste e a da Uleam. Algumas especificidades do curso da Uleam são: uma disciplina, cujo conteúdo trata sobre eventos, ministrada na língua inglesa, assim como na oferta de disciplinas relacionadas aos sistemas de informações e a gestão de banco de dados.

Verifica-se que a disciplina de Assessoria e Consultoria Empresarial é ofertada apenas pelo curso da Unioeste. Outra temática que se diferencia nesse curso é a Gestão Secretarial. Esse resultado pode sinalizar que o curso da Unioeste possui uma visão mais ampla sobre o campo de atuação do profissional de Secretariado Executivo, uma vez que o curso da Uleam insere maior quantidade de temáticas elementares em relação à atuação profissional como é o caso das rotinas de escritório. Cabe esclarecer que também foi indagado à coordenadora da Uleam sobre a inexistência dos conteúdos de Assessoria e Consultoria naquele curso, o que foi confirmado pela coordenadora, ao ressaltar que em nenhuma disciplina essa abordagem é realizada, segundo as ementas.

O último quadro apresenta o comparativo da matriz curricular do SE da Unioeste: Área Comunicação - Brasil versus Equador. 
Quadro 5- Comparativo matriz curricular Secretariado Executivo: Área Comunicação - Brasil x Equador

\begin{tabular}{|c|c|}
\hline $\begin{array}{c}\text { Disciplina área Comunicação } \\
\text { Unioeste - Brasil }\end{array}$ & $\begin{array}{c}\text { Disciplina área Comunicação } \\
\text { Uleam - Equador }\end{array}$ \\
\hline $\begin{array}{l}\text { Língua Portuguesa I (136h) } \\
\text { Língua Inglesa I e II (272h) } \\
\text { Língua Espanhola I e II (272h) } \\
\text { Inglês para Negócios I e II (136h) } \\
\text { Espanhol para Negócios I e II (136h) }\end{array}$ & $\begin{array}{l}\text { *Expressão oral e escrita }(192 \mathrm{~h}) \\
\text { Redação Básica }(128 \mathrm{~h}) \\
\text { Redação intermediária }(128 \mathrm{~h}) \\
\text { Redação Comercial }(128 \mathrm{~h}) \\
\text { *Redação Oficial }(128 \mathrm{~h}) \\
\text { **Ortografia }(128 \mathrm{~h}) \\
\text { *Ortografia e estrutura gramatical }(192 \mathrm{~h}) \\
\text { Relações Públicas }(96 \mathrm{~h} / 128 \mathrm{~h}) \\
\text { Basic English }(128 \mathrm{~h} / 192 \mathrm{~h}) \\
\text { Advanced English }(192 \mathrm{~h} / 128 \mathrm{~h}) \\
\text { Business English }(192 \mathrm{~h}) \\
\text { Fundamental English }(192 \mathrm{~h} / 128 \mathrm{~h}) \\
\text { Lower Intermediate English }(128 \mathrm{~h} / 192 \mathrm{~h}) \\
\text { Upper Intermediate English }(128 \mathrm{~h}) \\
\text { Intermediate Business English }(128 \mathrm{~h}) \\
\text { Advanced Business English }(192 \mathrm{~h}) \\
\text { **Effective Writing }(128 \mathrm{~h}) \\
\text { **Writing to Composing } \\
\text { **Strategic Reading }(128 \mathrm{~h}) \\
\text { **Translation Techniques }(128 \mathrm{~h}) \\
\text { **Effective Reading }(128 \mathrm{~h}) \\
\text { **Translation Application }(128 \mathrm{~h}) \\
\text { **Advanced Reading }(128 \mathrm{~h})\end{array}$ \\
\hline
\end{tabular}

Fonte: as autoras (2017)

*Disciplinas ministradas exclusivamente no Curso de Secretariado Ejecutivo.

** Disciplinas ministradas exclusivamente no Curso de Secretariado Ejecutivo Bilingüe

Quanto às disciplinas de línguas, verifica-se que a Uleam possui maior subdivisão de temáticas relacionadas à língua materna como, por exemplo, expressão oral e escrita; redação básica; redação intermediária; redação oficial; ortografia; ortografia e estrutura gramatical. Ao passo que, o curso da Unioeste oferta apenas uma disciplina relacionada especificamente à Língua Portuguesa e duas mais relacionadas à comunicação na empresa (Comunicação Empresarial I e II).

As disciplinas de língua estrangeira na Uleam concentram-se apenas na língua inglesa enquanto na Unioeste há oferta da língua inglesa e espanhola. Por outro lado, verifica-se que a língua inglesa na Uleam abrange disciplinas específicas de técnicas de tradução, não contempladas no curso da Unioeste dessa forma.

Finalmente, cabe destacar algumas disciplinas que não foram contempladas nas tabelas, pois estão relacionadas à metodologia científica e aos requisitos para conclusão do curso. No caso do curso do SE da Unioeste contemplam-se: Iniciação ao conhecimento científico (68h); Metodologia de Pesquisa (68h); Estágio Supervisionado (272h) e Trabalho de Conclusão de curso (204h). Já no curso de SE de Manabí são as seguintes disciplinas: 
Metodologia de Pesquisa (128h); Introdução à Investigação Científica (128h); Redação Científica (128h); Desenho teórico de Investigação Científica (128h) e Desenvolvimento de Trabalho Final de curso (128h).

Em geral, as disciplinas relacionadas à metodologia científica estão bastante próximas na comparação entre os cursos. No entanto, quanto aos requisitos para conclusão da carreira, constata-se que o estágio supervisionado não está contemplado no curso de SE da Uleam.

\section{Considerações Finais}

Este estudo ganha relevância ao permitir avaliar as possibilidades de internacionalização dos cursos de SE do Brasil, em especial, o da Unioeste, com instituições de ensino de países mais próximos ao Brasil. E, concomitantemente, amplia o conhecimento nessa área, considerada em construção.

Durante a investigação de campo chamou a atenção que apenas o Equador oferece cursos de SE com titulação de bacharelado. Esse achado desafia os cursos de SE a buscar alternativas para a mobilidade acadêmica, pois há necessidade de encontrar cursos com disciplinas relacionadas à área e que possam ser aproveitadas para enriquecer o currículo dos discentes. Nessa perspectiva, é relevante pensar em outras alternativas além do ensino formal e comparação entre as matrizes curriculares, tais como a realização de estágios, atividades de extensão e o aprimoramento da língua espanhola. Outro aspecto evidenciado, quando da comparação entre as matrizes curriculares, é que na matriz curricular da Uleam não são contempladas disciplinas, tais como Empreendedorismo e Assessoria e Consultoria Empresarial. Por outro lado, a Unioeste não oferece disciplinas do conteúdo do curso ministradas em inglês, como é o caso da Uleam em relação à disciplina de eventos, Events Organization.

Sabe-se que a América Latina não possui uma longa tradição de mobilidade acadêmica entre si, possivelmente porque se considera prioritariamente os centros de ensino dos países centrais. A internacionalização foi primeiramente uma tentativa de revolucionar as instituições para mais tarde tornar-se um processo que traria um caráter internacional para as funções acadêmicas de forma mais ampla. Nesse sentido, políticas públicas são necessárias para promover e regularizar a internacionalização do ensino, apoiar o reconhecimento de créditos acadêmicos e de graus obtidos no exterior, assim como fortalecer a formação de redes de pesquisa internacionais (Laus \& Morosini, 2005). 
Esses autores afirmam que a internacionalização da educação superior existe em diferentes níveis dependendo da instituição envolvida: nacional, institucional, individual e profissional. Como a internacionalização fortalece cada um desses níveis depende da cultura de cada instituição de ensino e das políticas públicas destinadas a esse processo. Portanto, é essencial gerar discussão nos círculos acadêmicos e governamentais sobre as motivações e os resultados esperados com a internacionalização e para isso há necessidade de acionar-se também os mecanismos de gestão da instituição de ensino.

Nesse sentido, ressalta-se que dentre as principais políticas públicas para a América Latina e Caribe, estão: a melhoria da educação e o desenvolvimento de competências; o fomento ao financiamento e maior integração entre as cadeias globais de valor, embora haja como ressaltado por Laus e Morosini (2005) falta de estratégia clara para essas ações.

Nessa direção, verificou-se que algumas políticas de ensino na América Latina, onde se incluem os países sul-americanos investigados, destinaram-se à realização de mudanças na concepção do processo de aprendizagem dos alunos nos níveis médio e superior. Uma dessas políticas refere-se ao Sistema de Créditos Acadêmicos, amplamente adotado pelos países investigados. Esta constatação aponta que as IES desses países estão mais alinhadas entre si e com as IEs na Europa, quanto à utilização de créditos. Da mesma forma, de acordo com Restrepo (2005), na Comunidade Europeia, o programa Erasmus buscou a unificação dos créditos acadêmicos para reconhecimento do trabalho acadêmico dos alunos e o aumento da mobilidade acadêmica dos estudantes, culminando na criação do sistema "European Community Course Credit Transfer System" (ICTS).

Segundo Restrepo (2005), o sistema de créditos acadêmicos permite aos estudantes contar com maior flexibilidade no processo de formação. Isso é possível porque são definidas dinâmicas pedagógicas da trajetória de formação acadêmica em associação com o professor, para que a distribuição de períodos de dedicação acadêmica ocorra de acordo com ritmos, velocidades, intensidades e sequências de aprendizagem. Dessa maneira, esse sistema fomenta a autonomia dos estudantes em função do trabalho independente, permitindo um processo de aprendizagem flexível e aberto em relação aos mecanismos de mobilidade e pluralidade acadêmica.

Como a possibilidade de mudanças na atual concepção do processo de ensinoaprendizagem no Brasil, em função dos créditos acadêmicos, é complexa, resta apenas buscar adaptação quando o assunto é a mobilidade acadêmica. Sendo assim, sugere-se que os cursos que almejam a internacionalização atentem para a avaliação da compatibilidade entre as 
matrizes curriculares. Com isso, os estudantes interessados em realizar mobilidade acadêmica na Uleam poderão se planejar com vistas a um melhor aproveitamento das disciplinas cursadas no período de permanência no exterior.

Ressalta-se que alguns desafios se apresentam no desenvolvimento das atividades de internacionalização. O primeiro é a urgente semestralização total do curso, visando maior flexibilidade em adaptações curriculares nos casos de mobilidade acadêmica de natureza interinstitucional e internacional.

O segundo desafio é que docentes e discentes obtenham conhecimento razoável das línguas dos países parceiros. O terceiro é a internacionalização de um currículo que não sirva apenas à mobilidade acadêmica, mas, também permita àqueles alunos que não tenham oportunidade de se deslocar ao exterior aprendam competências globais, internacionais e interculturais. Isso é possível por meio de um currículo delineado para esse fim.

Entende-se que esse movimento de buscar a inserção de fatores globais, internacionais e interculturais na pesquisa, ensino e extensão é internacionalizar "em casa". Isso parece ser viável aos cursos de graduação em SE que são minoria na América do Sul e, portanto, deverão buscar cooperações com países mais distantes. Para isso, sugere-se mapear todos os cursos de graduação em SE existentes em outros países.

Como limitação do estudo, ressalta-se a impossibilidade de aprofundar a pesquisa sobre cada conteúdo das disciplinas. Sendo assim, é que se faz uma outra sugestão de estudos futuros. Ou seja, compreender de forma mais aprofundada os conteúdos contemplados na matriz curricular do curso da Uleam, visando facilitar as equivalências entre os cursos. Além disso, pode-se avaliar as novas ideias do curso da Uleam quanto ao delineamento da matriz curricular do SE da Unioeste, resguardando-se as especificidades nacionais/locais.

\section{Referências}

Altbach, P. G. (2002). Knowledge and education as international commodities: The collapse of the common good. Current Issues. Catholic Higher Education. USA, 22, pp. 2-5.

Altbach, P. G., Reisberg, R. \& Rumbley, L. E. (2009). Trends in global higher education: tracking an academic revolution. Unesco, a report of the Word Conference on Higher Education. 
Aveiro, T.M.M. (2014). O programa Ciência sem Fronteiras como ferramenta de acesso à mobilidade internacional. Revista de Educação Ciência e Tecnologia. Rio Grande do Sul: Instituto Federal, 3 (2), pp.1-21.

Beelen, J. (2015). The long wait: researching the implantation of internationalization at home. Centre for Applied Research on Economics and Management (Carem, 2015). Hogeschool van Amsterdam, University of Applied Sciences The Netherlands.

Borges, G. da R. \& Amal, M. (2016). Internacionalização de cursos stricto sensu: uma investigação sobre a distância psíquica e as práticas adotadas. Revista GUAL (Revista Gestão Universitária na América Latina). Florianópolis: UFSC, 9 (2), pp. 260-281, maio.

Brasil (2008). Institui a rede federal de educação profissional científica e tecnológica e dá outras providências. Congresso Nacional. Lei 11.892, de 29 de dezembro de 2008.

Capes - Coordenação de Aperfeiçoamento de Pessoal de Nível Superior (2017). Avaliação da pós-graduação. Recuperado de: <http://www.capes.gov.br/avaliacao/ sobre-aavaliacao>.

De Wit, H. (2002). Internationalization of higher education in the United State and Europe. Westport: Greenwood. (Cap. 6, pp.104-119).

. (2011). Internationalization of higher education: nine misconceptions. International Higher Education, 34, summer, pp. 6-7.

Feilzer, M. Y. (2010). Doing mixed methods research pragmatically: Implications for the rediscovery of pragmatism as a research paradigm. Journal of Mixed Methods Research. Stanford/US, Sage: pp. 6-16.

Hudzik, J. K. (2011). Comprehensive internationalization: from concept to action. Washington: Nafsa,

Ilari, R. (2006). Linguística românica (3a ed.). São Paulo: Ática. 
Johanson, J. \& Vahlne, J. (1977). The internationalization process of the firm - a model of knowledge development and increasing foreign market commitments. Journal of International Business Studies. London/UK: Palgrave Macmillan, 8(1), pp. 23-32.

. (2013). The Uppsala model on evolution of the multinational business enterprise from internalization to coordination of networks. International Marketing Review. Bingley/UK: Emerald Group Publishing, 30, pp. 189-210.

Johanson, J. \& Wiedersheim-Paul, F. (1975). The Internationalization of the firm - Four Swedish Cases. Journal of Management Studies. Malden, EUA: Wiley On-line Library, 3(12), pp. 305-322.

Knight, J. (1994). Internationalization: elements and checkpoints. CBIE Research Paper, n. 7, Ottawa: Canadian Bureau for International Education. . (2004). Internationalization remodeled: definition, approaches, and rationales. Journal of Studies in International Education, 8(1), pp. 5-31.

. (2012). Student mobility and internationalization: trends and tribulations. Research in comparative \& international education, 7(1), pp.20-33.

. (2008). Higher education in turmoil: the changing world of internationalization. Rotterdam: Sense Publishers. Recuperado de: $<$ https://www.sensepublishers.com/media/475-higher-education-in-turmoil.pdf >.

Laus, S. P. \& Morosini, M. C. (2005). Internationalization of higher education in Brazil. In De Wit, H.; Jaramillo, I. C.; Gacel-Ávila, J. \& Knight, J. Higher education in Latin America: the international dimension. World Bank Group. (Eds.), pp. 111-148.

Leal, F. G. \& Moraes, M. C. B. (2017). Perspectivas de atuação do Secretário Executivo na gestão da internacionalização da educação superior. Revista de Gestão e Secretariado, 8(1), pp.138-167.

Leal, F.; Céspedes, R. R. \& Stallivieri, L. (2017). O perfil do gestor universitário de cooperação internacional no Brasil. Revista Eletrônica de Negócios Internacionais. São Paulo, 12(2), 1-16, maio/ago. 
Leask, B., Hunter, F. \& Rumbley, L. (2014). Editorial. Journal of Studies in International Education, 18(1), pp. 3-5.

Leite, D. \& Genro, M. E. H. (2012). Avaliação e internacionalização da educação superior: quo vadis América Latina? Avaliação, Campinas; Sorocoba, SP, 17(3), pp.763-785

Lima, M. C. \& Contel, F. B. (2011). Internacionalização da Educação Superior: Nações ativas, nações passivas e a geopolítica do conhecimento. São Paulo: Alameda.

Lopes, João R.C. (2015). Assimetria de distância psíquica: uma medição extrarregional no Brasil. Dissertação de Mestrado. Rio de Janeiro, UFRJ.

Maçaneiro, M. B. \& Kühl, M. R. (2013). Estado da arte e o rumo do conhecimento científico em secretariado executivo: mapeamento e análise de áreas de pesquisa. $R$. G. Secr., GESEC, 4(3), pp. 157-188.

Moreira, A. F. B. \& Candau, V. M. (2007). Indagações sobre o currículo: currículo, conhecimento e cultura. MEC/SEB, Brasília, 2007. Recuperado de: < http://portal.mec.gov.br/seb/arquivos/pdf/Ensfund/indag3.pdf $>$.

Moreira, A. F. B. \& Silva, T. T. (1994) Sociologia e teoria crítica do currículo: uma introdução. In: Moreira, A. F. B.; Silva, T. T (Orgs.). Currículo, cultura e sociedade. São Paulo: Cortez.

Morosini, M. C. (2006). Estado do conhecimento sobre internacionalização da educação superior: conceitos e práticas. Educar, Editora UFPR, 28, pp. 107-124.

Paige, R. M. (2005). Internationalization of higher education: performance assessment and indicators. Journal Nagoya, 8(5), pp. 99-122. Retrieved from: <http://www.cshe. nagoya-u.ac.jp/publications/journal/no5/08.pdf >.

Restrepo, J. M. (2005) El sistema de créditos académicos en la perspectiva colombiana y Mercosur: aproximaciones al modelo europeo. Revista de la Educación Superior, 3(135), jul.-set., pp. 131-152. 
Rodrigues, F. (2016). Ciências sem fronteiras muda e deixa de fora estudantes da graduação. Recuperado de: https://fernandorodrigues.blogosfera.uol.com.br/2016/07/23/cienciasem-fronteiras-muda-e-deixa-de-fora-estudantes-da-graduacao.

Rudzki. R. E.J. (2000) Implementing internationalization: the practical application of the fractal process model. Journal of Studies in International Education, 4, Fall, pp. 77-90.

Sacristán. J. G. (2002) Educar e conviver na cultura global: as exigências da cidadania. Porto Alegre: Artmed.

Santos, B.S. (2011). Universidade do Século XXI: para uma reforma democrática e emancipatória da Universidade. São Paulo: Editora Cortez.

Uleam - Universidad Laica Eloy Alfaro de Manabí (2017). Facultad de Gestión, Desarrollo y Secretariado Ejecutivo. Recuperado de: <http://carreras.uleam.edu.ec/secretariadoejecutivo/>.

Unioeste - Universidade Estadual do Oeste do Paraná. (2017). Projeto político-pedagógico do Curso de Secretariado Executivo. Toledo/PR: Colegiado Secretariado.

Van Der Wende, M. (1999). An innovation perspective on internationalization of higher education: the critical phase. Journal of Studies in International Education, 3, Spring, pp.3-14.

. (2003). Globalization and access to higher education. Journal of Studies in International Education, 7, summer, pp. 193-206, 2003.

Vigorena, D. A. L. (2017). Internacionalização na pós-graduação stricto sensu em administração. Tese de Doutorado, 2017. Universidade Positivo, Programa Mestrado e Doutorado em Administração, Curitiba, BR-PR

Yin, R. K. (2015). Estudo de caso: planejamento e métodos (3a ed.). Porto Alegre: Bookman. 